\title{
PhoR/PhoP two component regulatory system affects biocontrol capability of Bacillus subtilis NCD-2
}

\author{
Qinggang Guo, Shezeng Li, Xiuyun Lu, Baoqing Li and Ping Ma \\ Institute of Plant Protection, Hebei Academy of Agricultural and Forestry Sciences, \\ Integrated Pest Management Centre of Hebei Provence, Baoding, China.
}

\begin{abstract}
The Bacillus subtilis strain NCD-2 is an important biocontrol agent against cotton verticillium wilt and cotton sore shin in the field, which are caused by Verticillium dahliae Kleb and Rhizoctonia solani Kuhn, respectively. A mutant of strain NCD-2, designated M216, with decreased antagonism to V. dahliae and $R$. solani, was selected by mini-Tn 10 mutagenesis and in vitro virulence screening. The inserted gene in the mutant was cloned and identified as the phoR gene, which encodes a sensor kinase in the PhoP/PhoR two-component system. Compared to the wild-type strain, the APase activities of the mutant was decreased significantly when cultured in low phosphate medium, but no obvious difference was observed when cultured in high phosphate medium. The mutant also grew more slowly on organic phosphate agar and lost its phosphatidylcholine-solubilizing ability. The suppression of cotton seedling damping-off in vivo and colonization of the rhizosphere of cotton also decreased in the mutant strain when compared with the wild type strain. All of these characteristics could be partially restored by complementation of the phoR gene in the M216 mutant.
\end{abstract}

Key words: Bacillus subtilis, antagonism, Verticillium dahliae, mini-Tn10.

Received: July 23, 2009; Accepted: November 17, 2009.

\section{Introduction}

Cotton is one of the major crops in China as well as in the world. Verticillium wilt, caused by Verticillium dahliae Kleb is a devastating disease in cotton, causing heavy economic losses globally (Tjamos et al., 2000). This disease is difficult to control due to the absence of resistant varieties, the long viability of the resting structures, and the inability of fungicides to inhibit the pathogen once inside the xylem (Fradin and Thomma, 2006). Therefore, research on alternative management strategies for cotton verticillium wilt control is important. One alternative is the use of antagonistic microorganisms which can suppress soil-borne pathogens in the rhizosphere of cotton (Weller et al., 2002; Tjamos et al., 2004). There are several reports on treatments with such beneficial organisms providing a pronounced reduction in plant disease, both in greenhouses and in the field. One example is the gram-positive bacterium Bacillus subtilis, a bacteria widely distributed in nature, and which has been found to possess bio-control potential for a variety of phytopathogenic fungi (Leifert et al., 1995; Podile and Prakash, 1996). The mechanisms by which $B$. subtilis reduces plant diseases include antagonism

Send Correspondence to Ping Ma. Institute of Plant Protection, Hebei Academy of Agriculture and Forestry Sciences, 437\# Dongguan street, 071000 Baoding, Hebei, China. E-mail: pingma88@126.com. of fungal pathogens by competing for niche and nutriments (Handelsman and Stabb, 1996), by producing fungitoxic compounds (Toure et al., 2004; Leclere et al., 2005), and stimulating the defensive capacities of the host plant (Ongena et al., 2004).

Two-component regulatory systems are major mechanisms by which $B$. subtilis strains sense environmental stimuli and respond by specific gene activation (Parkinson and Kofoid, 1992). These systems depend upon histidine kinases that serve both to sense a particular stimulus and to transmit the information to the response regulator via a phosphoryl-transfer reaction, and to up- or down-regulate the expression of specific target genes (Hoch, 2000). To date, more than 35 two-component regulatory systems have been identified in B. subtilis by genome sequencing, these functioning in the adaptation to environmental stress (Darmon et al., 2002), the production of secondary metabolites (Martin, 2004), and cell division (Fukuchi et al., 2000). Further functions may be discovered by mutagenesis studies.

PhoP/PhoR is one such important two-component regulatory system in B. subtilis and other gram-negative and gram-positive bacteria. In response to phosphate deficiency, PhoR, a histidine sensor kinase, phosphorylates its cognate response regulator $\mathrm{PhoP}(\mathrm{PhoP} \sim \mathrm{P})$ and either induces or represses $\mathrm{Pho}$ regulon genes by binding of $\mathrm{PhoP} \sim \mathrm{P}$ to $\mathrm{Pho}$ box 
sequences: direct repeats of TT(A/T/C)ACA with a $5 \pm 2$-bp spacer (Eder et al., 1999). At present, more than 30 genes classified as Pho regulon are controlled by the PhoP/PhoR system have been identified by proteomics and transcriptional studies (Antelmann et al., 2000; Pragai et al., 2004).

The $B$. subtilis NCD-2 was selected from rhizosphere of cotton and is an antagonist of $V$. dahliae and Rhizoctonia solani, the phytopathogens which cause damping-off disease in cotton seedlings. This strain was selected for further research because of its high efficacy in controlling cotton verticillum wilt and cotton seedling damping-off in the field, although its antifungal activity is not as effective as some other biocontrol strains (Li et al., 2005). Previous research also confirmed that the NCD-2 strain has the ability to solubilize phosphatidylcholine (Ma, unpublished). In this study, we used transposon mutagenesis to clone functional genes involved in the biocontrol activity of the NCD-2 strain. We report on the identification and characterization of a gene that is part of the $\mathrm{PhoP} / \mathrm{PhoR}$ twocomponent system in regulating the antifungal ability of NCD-2 against $V$. dahliae and phosphatidylcholine-solubilizing ability, as well as suppression of cotton damping-off.

\section{Materials and Methods}

\section{Bacteria strains, growth conditions, and plasmids}

The bacterial strains and plasmids used in this study are listed in Table 1. Escherichia coli DH5 $\alpha$ was used as the host for plasmid construction. All strains were grown in Luria Bertani (LB) medium supplemented when necessary with the appropriate antibiotic (for $E$. coli, ampicillin at $100 \mu \mathrm{g} / \mathrm{mL}$, erythromycin at $100 \mu \mathrm{g} / \mathrm{mL}$, tetracycline at $20 \mu \mathrm{g} / \mathrm{mL}$; for B. subtilis, chloramphenicol at $5 \mu \mathrm{g} / \mathrm{mL}$, erythromycin at $1 \mu \mathrm{g} / \mathrm{mL}$, tetracycline at $20 \mu \mathrm{g} / \mathrm{mL}$ ).

\section{Mini-Tn 10 mutagenesis and generation of the transposon library}

The B. subtilis strain NCD-2 was transformed with the plasmid pHV1249 by the protoplast fusion method (Martin et al., 1981), whereupon transformants were selected on LB agar containing $5 \mu \mathrm{g} / \mathrm{mL}$ chloramphenicol (Cm) and $1 \mu \mathrm{g} / \mathrm{mL}$ erythromycin (Em). Individual colonies of NCD-2 transformants carrying intact plasmid pHV1249 were inoculated into LB culture containing $5 \mu \mathrm{g} / \mathrm{mL} \mathrm{Cm}$. The cultures were grown with shaking at $30^{\circ} \mathrm{C}$. When the culture reached the logarithmic phase (optical density of $0.6-0.8$ at $660 \mathrm{~nm}$ ), it was diluted 100-fold in water, and $100 \mu \mathrm{L}$ samples of the diluted culture were spread onto LB agar plates containing $5 \mu \mathrm{g} / \mathrm{mL} \mathrm{Cm}$, and then incubated at $51{ }^{\circ} \mathrm{C}$ for the selection of transposants (Tsuge et al., 1999). Thermoresistant $\mathrm{Cm}^{\mathrm{r}}$ colonies were regarded as mini- $\mathrm{Tn} 10$ insertional mutants and the $\mathrm{Cm}^{\mathrm{r}} \mathrm{Em}^{\mathrm{s}}$ colonies were selected for the antagonism assay.

\section{Screening of mutants for loss of antifungal ability against Verticillium dahliae}

For in vitro screening of transposants for loss of antagonistic activity against $V$. dahliae, well diffusion inhibition assays were conducted as described by Cintas et al. (1995) with the following modifications. The $V$. dahliae was grown for 4- to 6 days in potato dextrose broth (PDB) at $25^{\circ} \mathrm{C}$ and then filtrated by two layers of gauze. Soft agar was made by adding $0.7 \%$ agar to PDB, and to create an overlay. $V$. dahliae was added to the soft agar in a ratio of $2 \mathrm{~mL}$ of fungal culture per $100 \mathrm{~mL}$ soft agar $\left(10^{6} \mathrm{CFU} \mathrm{mL}^{-1}\right)$. From this mixture, $8 \mathrm{~mL}$ was overlaid onto each base plate (PDB containing 1.5\% agar) and allowed to solidify completely. Wild type B. subtilis strain NCD-2 and transposants were transferred with toothpicks onto the layered medium, one wild-type strain and eight transposants per dish. All plates were incubated for 3 to 4 days at $30^{\circ} \mathrm{C}$. The antifungal ability of both transposants and wild-type strain against $V$. dahliae was recorded as the size of the zone of

Table 1 - Bacterial strains or plasmids used in this study.

\begin{tabular}{lll}
\hline Strain or plasmid & Genotype or characteristics & Source \\
\hline B. subtilis & & \\
NCD-2 & Wide-type & Isolated from rhizophere of cotton \\
M216 & phoR::mini-Tn10 in strain NCD-2, Cm ${ }^{\mathrm{r}}$ & This study \\
Fungal & & \\
V. dahliae & Cause cotton Verticillium wilt & Lab stock \\
R. solani Kuhn & Cause cotton seedling damping-off & Lab stock \\
Plasmids & & \\
pHV1249 & Delivery plasmid for mini-Tn10 transposon, $\mathrm{Cm}^{\mathrm{r}} \mathrm{Em}^{\mathrm{r}} \mathrm{Ap}^{\mathrm{r}}$ & Lab stock \\
pHY300PLK & E.coli and Bacillus Shuttle vector, Ap $\mathrm{Tet}^{\mathrm{r}}$ & TaKaRa \\
pBluescript II SK \pm & Cloning vertor, Ap & Stratagene \\
\hline
\end{tabular}

Tet $^{\mathrm{r}}$, tetracycline resistance; $\mathrm{Cm}^{\mathrm{r}}$, chloramphenicol resistance; $\mathrm{Ap}^{\mathrm{r}}$, ampicillin resistance; $\mathrm{Kan}^{\mathrm{r}}$, kanamycin resistance. 
fungal inhibition. Mutants with decreased antagonism against $V$. dahliae were also used to test the antagonism against $R$. solani by the dual-culture method.

\section{Southern blot hybridization}

For Southern blot hybridization, an internal 700-bp fragment of mini-Tn10 was obtained by PCR with the primers mini-Tn10S (5'CGTTATTTGAGTTTATCACCCT3') and miniTn10A (5'TAAGTCTTCCCTTGTTATTGTG3'). This fragment was purified and labeled using a DIG High Prime DNA Labeling and Detection Starter Kit (Roche, Indianapolis). B. subtilis strain DNA was cleaved with EcoRI and PstI (TaKaRa), whereupon the fragments were separated on a $0.8 \%$ agarose gel, transferred to a nylon membrane, and then cross-linked by UV irradiation. Hybridization using the labeled fragment as a probe was carried out according to the instructions of the DIG-DNA Labeling and Detection Kit.

Cloning and sequencing of mini-Tn 10 insertions and complementation study

The flanking sequences of the mini-Tn 10 insertion were obtained by a nested PCR method. Chromosomal DNA from the mutant was extracted and used as a template with the anchor primer AP1 (supplied by TaKaRa company) and the specific primers SP1 (5'CATTGCTCTGAAAGCGGGAACG3'), $\quad$ SP2 (5'GCATCGTATTGCCCGAACAGATAA3'), and SP3 (5'GGCCAAGTTCGGTAAGAGTGAGA3'), which had been designed according to the mini- $\operatorname{Tn} 10$ sequence. The final products amplified with AP1 and SP3 primers were purified and sequenced, the homologues were identified by blastx programs.

To complement the M216mutant, a 2.64-kb DNA fragment containing the $p h o R$ gene was amplified with the primer set phoRS (5'CCaagcttTTTTCTGTCTGCCGCCTTTA3') and phoRA (5'CGggatccACCAAGCCGTTCAGTCCAAG3') (underlined letters indicate HindIII and BamHI restriction sites, respectively). The resulting PCR product was digested with HindIII and BamHI, and then cloned into the pHY300PLK plasmid to yield pHY300PLK-R (Figure 1). The recombinant plasmid pHY300PLK-R was first trans- formed into $E$. coli $\mathrm{DH} 5 \alpha$, extracted and then transferred to the M216 mutant by electrotransformation for the complementation study.

\section{Measurements of alkaline phosphatase (APase) activity and phosphatidylcholine-solubilizing ability}

In order to measure APase activity, cells were grown in low-phosphate $(0.065 \mathrm{mM}$ phosphate) or high-phosphate (10 mM phosphate) medium for 1,2 or 3 days. Cells were harvested by centrifugation at $12,000 \mathrm{rpm}$ for $15 \mathrm{~min}$, washed with sterile distilled water, suspended with $50 \mathrm{mM}$ Tris $(\mathrm{pH} 7.5)$ and dispersed ultrasonically $(20 \mathrm{kz}, 2 \mathrm{~A}$, $60 \mathrm{~Hz}$ ) for $40 \mathrm{~min}$ in ice water (Raso et al., 2008), before measuring APase activity by using Olsen's method (Olsen and Sommers, 1982). Qualitative comparison of phosphatidylcholine-solubilizing ability were performed on Mongina organic phosphate agar plates. B. subtilis strains were transfered to Mongina organic phosphate agar plates $\left(0.5 \mathrm{~g} / \mathrm{L} \quad\left(\mathrm{NH}_{4}\right)_{2} \mathrm{SO}_{4} ; 0.3 \mathrm{~g} / \mathrm{L} \quad \mathrm{NaCl} ; 0.3 \mathrm{~g} / \mathrm{L}\right.$ $\mathrm{MgSO}_{4} .7 \mathrm{H}_{2} \mathrm{O} ; 0.3 \mathrm{~g} / \mathrm{L} \quad \mathrm{KCl} ; 0.03 \mathrm{~g} / \mathrm{L} \quad \mathrm{FeSO}_{4} .7 \mathrm{H}_{2} \mathrm{O}$; $0.03 \mathrm{~g} / \mathrm{L} \mathrm{MnSO}_{4} .4 \mathrm{H}_{2} \mathrm{O} ; 5 \mathrm{~g} / \mathrm{L} \mathrm{CaCO}_{3} ; 10 \mathrm{~g} / \mathrm{L}$ glucose $; 1.5 \%$ agar; $85 \mathrm{~mL} / \mathrm{L}$ egg yolk solution), and to assess growth and qualitatively compare phosphatidylcholine-solubilizing abilities after incubation at $37^{\circ} \mathrm{C}$ for 5 to 7 days.

\section{Root colonization and biocontrol of cotton seedling damping-off}

To evaluate the biocontrol capability against cotton seedling damping-off and root colonization, the $B$. subtilis strains NCD-2/pHY300PLK and M216/pHY300PLK were used to represent the $B$. subtilis NCD-2 wild-type and M216 mutant, respectively. All strains were grown at $30^{\circ} \mathrm{C}$ for $30 \mathrm{~h}$ in LB medium, cell were harvested by centrifugation at 12,0000 rpm for $30 \mathrm{~min}$, and the cells were adjusted with sterile distilled water to obtain the desired bacterial concentration for seed treatment $\left(\mathrm{OD}_{550}=5\right)$. Cotton seeds (Gossypium hirsutum cv. Jimian99B) were surface sterilized and germinated before sowing by washing three times with sterile distilled water and soaking for $15 \mathrm{~min}$ in the bacterial suspension mentioned above or in sterile distilled water as a control. In every experiment, 84 seeds were used for each treatment. The seeds were dried under the laminar flow and sown in plastic packs contain-

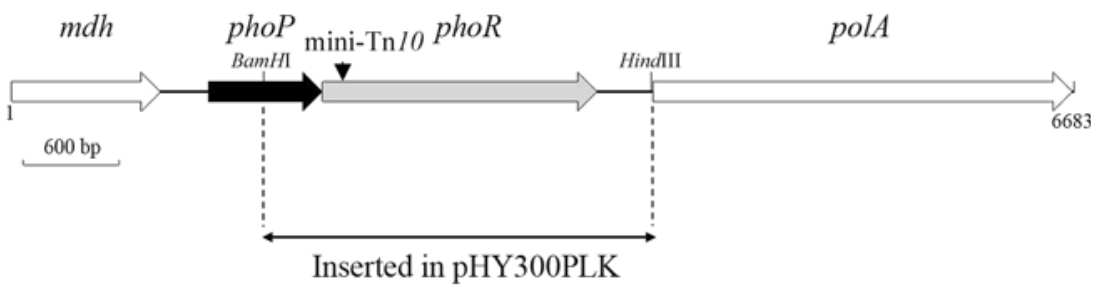

Figure 1 - Schematic diagram of B. subtilis NCD-2 $m d h$, phoP, phoR and polA genes. Single-headed arrows represent the location and orientation of genes in the $B$. subtilis NCD-2 chromosome. Main restriction enzyme sites are shown, the mini-Tn 10 in M216 mutants being inserted into the phoR gene. For M216 mutant phoR gene complementation, the gene itself was inserted into a pHY300PLK plasmid. 
ing growth substrate (sterilized soil: vermiculite 3:1), previously infected with $R$. solani by mixing with a suspension of mycelial fragments $\left(10^{5}\right.$ propagules. $\mathrm{g}^{-1}$ soil). The trays were incubated in a greenhouse to maintain the temperature at $28{ }^{\circ} \mathrm{C}$ at $95 \%$ relative humidity with a photoperiod of $16 \mathrm{~h}$.

The initial bacterial inoculum per seed was determined by suspending 10 seeds in $5 \mathrm{~mL}$ sterile water, vortexing for $10 \mathrm{~min}$ and then spreading $50 \mu \mathrm{L}$ serially diluted samples on an LB agar medium containing $20 \mu \mathrm{g} / \mathrm{mL}$ tetracycline. The plates were incubated at $30^{\circ} \mathrm{C}$ for $24 \mathrm{~h}$, and the representative colonies were subsequently counted.

To monitor $B$. subtilis NCD-2 and its derivative strains colonization in the cotton rhizospheres, at 8 and 16 days after sowing, three plants per treatment were carefully removed from the soil and roots with adhering soil were cut and tested by plating-PCR with $B$. subtilis NCD-2 strainspecific primers RT-phoRA (5'ACTTGGCTTCGCTTCTTGAT3'), and RT-phoRS (5'TTTGGGAATCAGCCGCTCTC3'), (the result of a specific unpublished assay). Briefly, large aggregates of soil were gently removed from the roots and rhizosphere soil were collected and air-dried. The roots were carefully washed in $2 \mathrm{~mL}$ of $0.9 \% \mathrm{NaCl}$ solution to collect the still adhering rhizosphere soil. The roots were then removed from the solution and the bacterial cells were extracted for 5 min using a rotary shaker at maximum speed. The bacteria containing solutions were then serially diluted (1: 10-1: $10^{3}$ ) and $100 \mathrm{~mL}$ of each dilution were plated on LB agar plates supplemented with $20 \mu \mathrm{g} / \mathrm{mL}$ tetracycline (SigmaAldrich). After $24 \mathrm{~h}$ of incubation at $50^{\circ} \mathrm{C}$, colony numbers were recorded, and colonies similar to the wild-type strain were directly dissolved in PCR reaction tubes and tested with the RT-phoRA/RT-phoRS primer pair. After sampling, the remaining cotton seedlings were used for evaluating the biocontrol capability of $B$. subtilis NCD-2 and its derivative strains.

\section{Statistical analysis}

Three replicates were carried out to assess in vivo root colonization and bio-control capability of both $B$. subtilis NCD-2 and its derivative strains. All data were analyzed by two-way ANOVA using SAS for Windows ver. 9.0 software. Differences were considered to be significant at a 95\% (or higher) confidence level.

\section{Results}

Isolation and identification of mutants defective in antifungal ability against $V$. dahliae and $R$. solani

The NCD-2 strain, known to be well-capable of suppressing cotton verticillum wilt and cotton damping-off in seedlings, was identified as a Bacillus subtilis strain by $16 \mathrm{~S}$ rDNA sequencing (GenBank accession number FJ624484) and biochemical assaying. In order to clone the functional gene associated with antifungal activity from the NCD-2 strain, a transposon mutant library of B. subtilis NCD-2 was constructed with mini-Tn10, whereby more than $4000 \mathrm{Cm}^{\mathrm{r}} \mathrm{Em}^{\mathrm{s}}$ colonies were selected and screened for antibiosis activities against $V$. dahliae mycelial growth. Four mutants with decreased antagonism against $V$. dahliae were purified. As described in materials and methods, in vitro testing revealed that these mutants also expressed decreased antagonism against $R$. solani. Southern hybridization with a mini-Tn10 DNA fragment as a probe showed that all these mutants contained a single copy of inserted transposon which possibly localized at the same chromosomal location because the size of hybridized fragments in each mutant was identical (data not shown). One such mutant was designated as M216 and employed for further study.

\section{Cloning and sequencing of the genes involved in antifungal activity of NCD-2}

A $1.5 \mathrm{~kb}$ DNA fragment flanking the mini-Tn 10 in the M216 mutant was obtained by nested-PCR. Sequencing analysis showed significant similarity $(98 \%)$ between the transposon-disrupted gene in the M216 mutant and the phoR gene in B. subtilis 168, also known as a sensor kinase in the PhoP/PhoR two-component regulatory system (Figure 1). By using a complemented strain containing a plasmid-borne $p h o R$ gene, we showed that the antagonistic activity of M216 mutant against $V$. dahliae and $R$. solani could be significantly restored (Figure 2).

In B. subtilis, the PhoR/ PhoP two-component system regulates the biosynthesis of certain secondary metabolites at the transcriptional and post-transcriptional levels when undergoing phosphate deprivation. The sequence of $\mathrm{PhoP} / \mathrm{PhoR}$ two-component system was obtained in strain NCD-2 through sequencing of its chromosomal DNA. The phoR gene (GenBank accession number EU165270) encodes a protein of 579 amino acids which has $98 \%$ identity with phoR of B. subtilis 168. The phoP gene of NCD-2 (GenBank accession number EU188794) encodes a protein of 239 amino acids which has $98 \%$ identity with $p h o P$ of $B$. subtilis 168.

\section{Quantitative measurements of APase activity}

B. subtilis can produce vegetative APase when phosphate becomes growth limiting (Bookstein et al. 1990) in a pathway that is mediated by the $\mathrm{PhoP} / \mathrm{PhoR}$ twocomponent regulatory system (Hulett et al., 1990). Since the APase of B. subtilis NCD-2 is mainly located intracellularly and only very small amounts can be detected extra-cellularly (data not shown), we only compared the activities of intracellular APase in B. subtilis NCD-2 wild-type, mutant and complemented strains cultured in high and low phosphate medium. The APase activity of $B$. subtilis NCD-2 wild-type was significantly lower in high phosphate medium than in low phosphate medium, consis- 

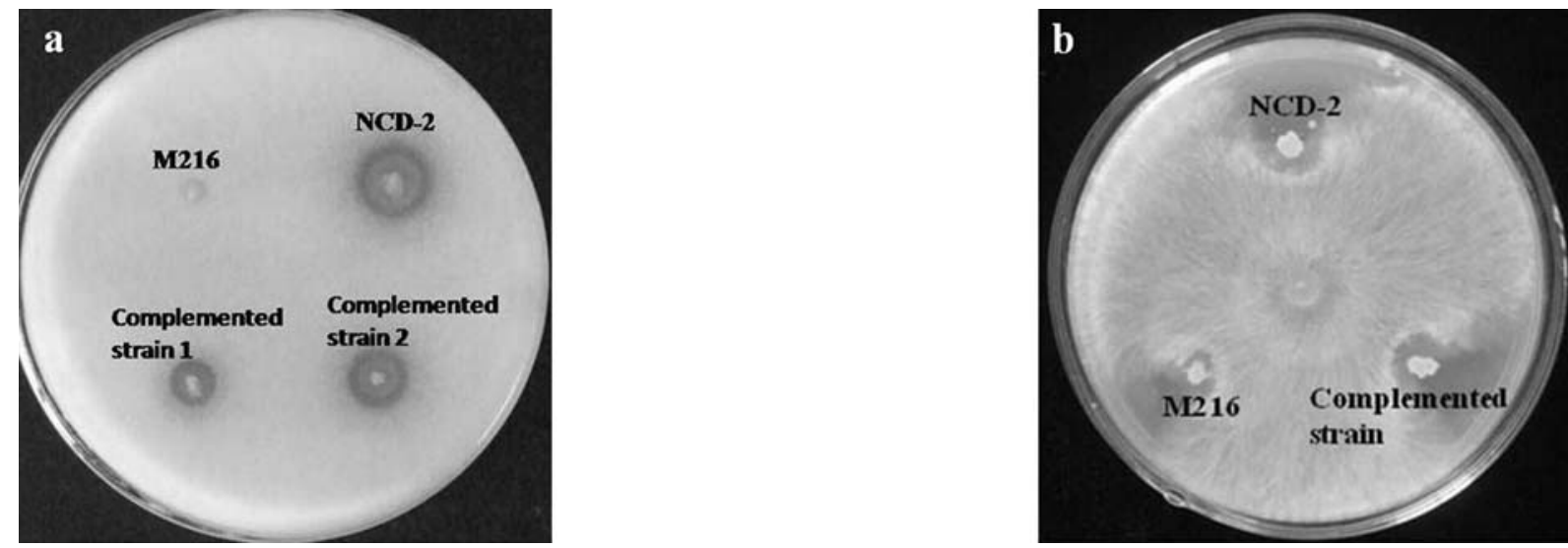

Figure 2 - Inhibition by B. subtilis NCD-2 wild-type and its derivative strains of in vitro growth of Verticillium dahliae (a) and Rhizoctomia solani (b). Double-layer culture assaying was employed to check $V$. dahliae inhibition, with antifungal capability being recorded according to the zone surrounding the colony. Dual-culture assaying was carried out to check $R$. solani inhibition, whereas antifungal capability was recorded according to the inhibition zone surrounding the colony.

tent with the results of previous research (Bookstein et al., 1990). When grown in high phosphate medium, no significant differences in APase activities among NCD-2 wildtype, mutant and complemented strains were observed. In low phosphate medium, however, the APase activity of M216 mutant was much lower than that of NCD-2 wildtype, and the APase activity of M216 mutant was nearly completely restored when complemented with the phoR gene (Figure 3a). The growth of NCD-2 wild-type and derivative strains were also compared, the results indicating no significant difference when cultured both in high and low phosphate media (Figure 3b). Thus, the result indicated that the phoR gene is involved in the APase activities in the NCD-2 strain.

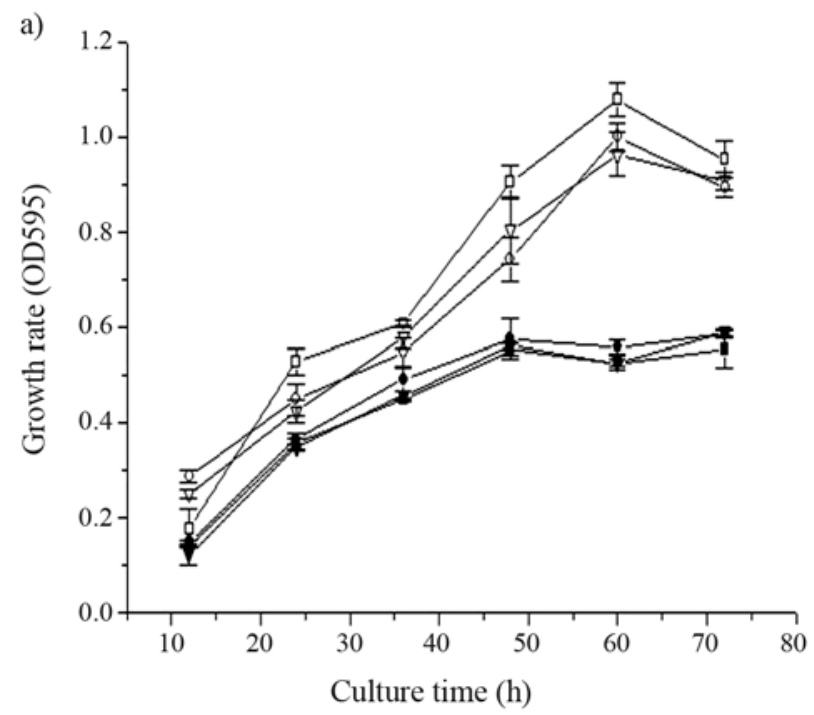

\section{Qualitative measurements of phosphatidylcholine-solubilizing ability}

In B. subtilis, phoD encodes a phosphodiesterase that may be involved in the hydrolysis of phosphatidylcholine, whereas $\mathrm{PhoP} / \mathrm{PhoR}$ positively regulates $p h o D$ expression (Hulett et al., 1990). Therefore, in this study we asked if the PhoR/PhoP two-component regulatory systemis involved in the abilities of the B. subtilis NCD-2 strain to solubilize and utilize phosphatidylcholine, as demonstrated by the clear zone surrounding each colony and the growth on organic phosphate culture media. Compared with the NCD-2 wild-type strain, the M216 mutant had decreased ability to solubilize phosphatidylcholine, and lost the ability to utilize phosphatidylcholine. Both abilities in the M216 mutant

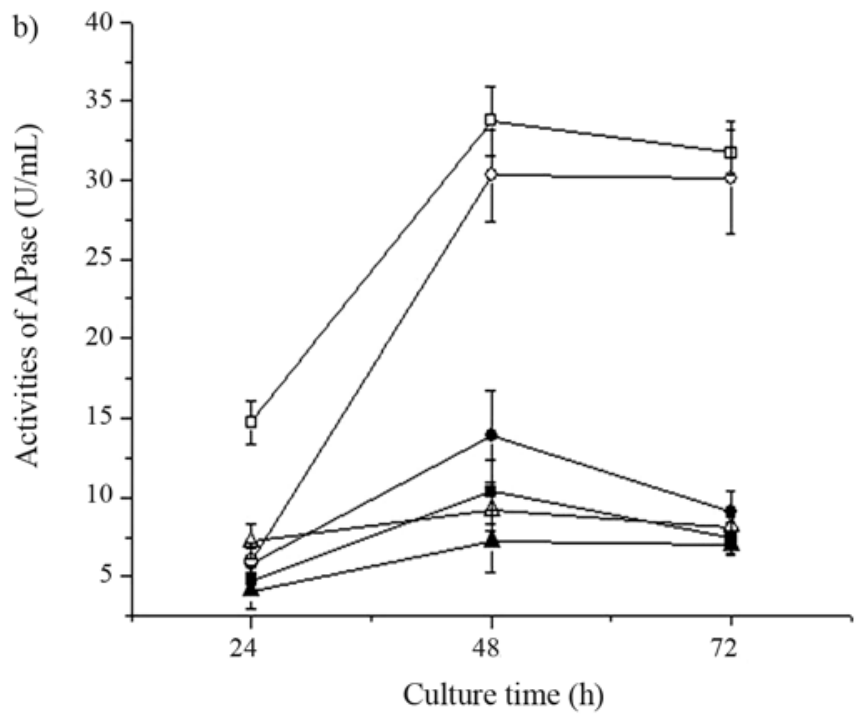

Figure 3 - Growth and alkaline phosphatase (APase) activities of B. subtilis NCD-2 and its derivative strains during growth in both a high and low phosphate medium. Samples were removed periodically, and APase activities assayed in cell extracts. The values are averages of three replications, with mean values \pm SD indicated. Squares, NCD-2 wild-type; triangles, M216 mutant; circles, M216 mutant complemented strain. Open symbols, cell growth in a high phosphate medium; closed symbols, cell growth in a low phosphate medium. 
were restored when complemented with phoR (Figure 4), indicating that they are specifically regulated by this gene in the NCD-2 strain. However, whether the regulation of phoR is mediated by $p h o D$ should be investigated in future studies.

\section{Biocontrol of cotton seedling damping-off}

The NCD-2 strain possesses antagonistic properties against $R$. solani and can effectively suppress cotton seedling damping-off in the field. Pre-treatment of cotton seeds with vegetative cells of the wild-type NCD-2 strain provided consistent protection against cotton damping-off disease, as observed through three independent experiments. By assessing the percentage of healthy seedlings, the capacity in suppressing cotton seedling damping-off was less in M216 mutants than in the wild-type NCD-2 strain, although becoming partially restored in the complemented M216 mutant (Table 2).

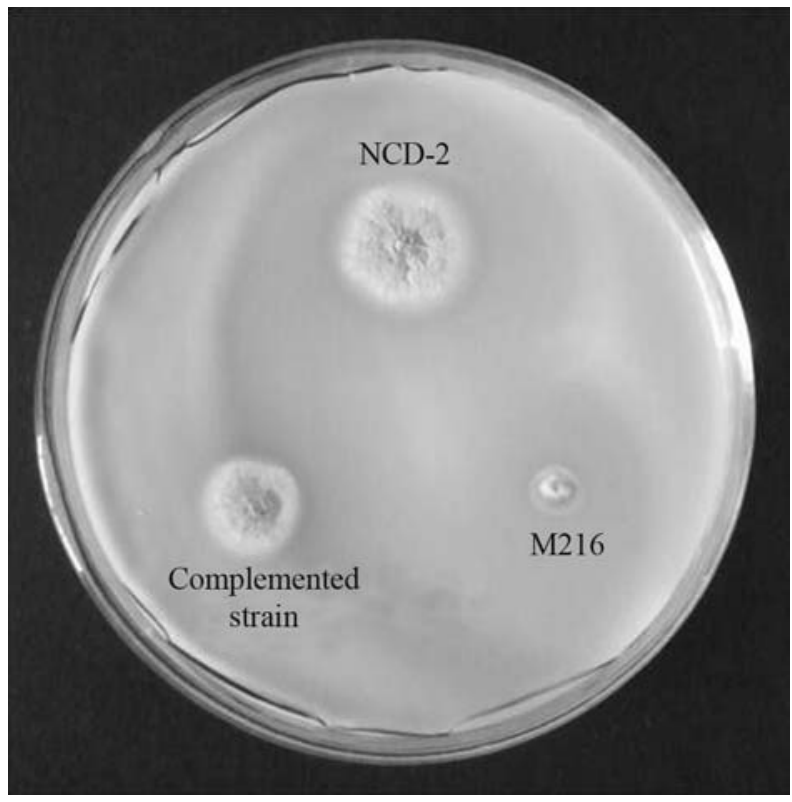

Figure 4 - Growth and phosphatidylcholine-solubilizing ability of $B$. subtilis NCD-2 wild-type strain and derivative strains. The growth and phosphatidylcholine-solubilizing ability were recorded according to the diameter of the colony and zone around the colony, respectively, the results being recorded after incubation for 5 days at $37^{\circ} \mathrm{C}$.
Table 2 - Effect of strain NCD-2 and its derivative strain on the reduction of damping-off of cotton plants caused by Rhizoctonia solani Kuhn in greenhouse.

\begin{tabular}{lc}
\hline Treatments & Healthy seedlings $(\%)^{*}$ \\
\hline Control & $53.57 \pm 8.2 \mathrm{a}$ \\
M216 & $58.60 \pm 6.7 \mathrm{ab}$ \\
Complemented strain & $70.01 \pm 8.0 \mathrm{~b}$ \\
NCD-2 wild type & $71.82 \pm 7.1 \mathrm{~b}$ \\
\hline
\end{tabular}

The percentage of healthy seedlings was recorded 2 weeks after inoculation, with sterilized-water-treated seeds as control. The values are averages of three replications, the mean values $\pm \mathrm{SD}$ are indicated. In the same column, the same letters are not significantly different $(\mathrm{p} \leq 0.05)$ on using ANOVA least-significant-difference testing.

\section{Monitoring B. subtilis NCD-2 and derivative strains on cotton roots}

After application on cotton seeds at a concentration of $1.08 \times 10^{5}-1.39 \times 10^{5} \mathrm{CFU} /$ seed, the population level of $B$. subtilis NCD-2 and derivative strains in cotton rhizospheres was evaluated through selection in antibiotics and by plating-PCR. More than $96 \%$ of the colonies tested by PCR in the plating method were identified as B. subtilis NCD-2 or derivative strains. Eight days post-sowing, there was no significant difference in the population density of $B$. subtilis NCD-2 wild-type and derivative strains in the rhizospheres, but 16 days after sowing the population density of the M216 mutant was lower only at $114 \mathrm{CFU}$ ( $\mathrm{g}$ wt soil) $)^{-1}$, whereas the population density of the NCD-2 wild-type strain was $3.08 \times 10^{3} \mathrm{CFU}$ ( $\mathrm{g}$ wt soil) ${ }^{-1}$, thus significantly higher than the the population density of M216 mutant. The population density of the phoR complemented strain was also higher than that of M216 mutant, but not significantly different when compared to $B$. subtilis $\mathrm{NCD}-2$ wild-type (Table 3). Therefore, it can be inferred that colonization of B. subtilis NCD-2 was regulated by the phoR gene.

\section{Discussion}

The PhoP/PhoR two-component system regulates the biosynthesis of some secondary metabolites at the transcriptional and post-transcriptional level under phosphate-

Table 3 - Colonization of $B$. subtilis NCD-2 and derivative strains on root of cotton seedlings.

\begin{tabular}{lccc}
\hline Treatments & Initial bacterial density $(\mathrm{CFU}$ per seed)* & \multicolumn{2}{c}{ Bacterial cell count $(\mathrm{CFU}$ g-1 soil)* } \\
\cline { 3 - 4 } & & 8 days & 16 days \\
\hline NCD-2/pHY300PLK & $1.19 \times 10^{5} \mathrm{a}$ & $3.98 \times 10^{3} \mathrm{a}$ & $3.08 \times 10^{3} \mathrm{a}$ \\
Complemented strain & $1.08 \times 10^{5} \mathrm{a}$ & $3.87 \times 10^{3} \mathrm{a}$ & $2.29 \times 10^{3} \mathrm{ab}$ \\
M216/pHY300PLK & $1.39 \times 10^{5} \mathrm{a}$ & $2.95 \times 10^{3} \mathrm{a}$ & $0.14 \times 10^{3} \mathrm{~b}$ \\
\hline
\end{tabular}

*The values are averages of three replications, with mean values indicated. In the same column, the same letters are not significantly different ( $\mathrm{p} \leq 0.05)$, on using ANOVA least-significant-difference testing. 
deprived conditions (Martin, 2004). In Streptomyces lividans, several antibiotics have been shown to be negatively regulated by the PhoR/PhoP system (Sola-Landa et al., 2003). In B. subtilis, more than 30 genes were classified as belonging to the pho regulon and being controlled by the PhoR/PhoP system (Martin, 2004), and by genome-wide transcriptional analysis increasingly more genes were identified as belonging to the pho regulon (Allenby et al., 2005), However, to our knowledge, no antibiotics have been identified as being controlled by this two-component system in $B$. subtilis. In this study, the PhoP/PhoR twocomponent regulatory system was cloned from $B$. subtilis NCD-2 and the phoR gene was disrupted by mini-Tn 10 . We found that the selected M216 mutant strain had decreased antagonism against $V$. dahliae and $R$. solani, and complementation of phoR could restore the antagonistic activity of this mutant. Therefore, we concluded that the antagonistic activities of B. subtilis NCD-2 against $V$. dhaliae and $R$. solani are controlled by the PhoR/PhoP two-component system. However, we do not yet know what antibiotics or metabolites are controlled by the PhoR/PhoP system.

B. subtilis can produce APase or phosphodiesterase (PDase) when phosphate becomes growth-limiting (Bookstein et al., 1990), this process being mediated by the PhoR/PhoP two-component system (Hulett et al., 1990). We compared the APase activities from the intracellular compartment where it is mainly located in B. subtilis NCD-2 wild-type, mutant and complemented strains cultured in high and low phosphate media. APase activities in the NCD-2 wild-type strain were higher when encountering phosphate starvation, and lower in the phoR disrupted strain than in the NCD-2 wild type when cultured in low phosphate medium but not different when cultured in high phosphate medium, thus confirming $p h o R$ involvement in the regulation of APase genes in the NCD-2 strain.

In B. subtilis, encoding APase genes (phoA, phoB) and the PDase gene $(p h o D)$ are induced by PhoR/PhoP regulators on undergoing phosphate starvation (Le Hegarat and Anagnostopoulos, 1973). phoD encodes a phosphodiesterase possibly involved in the hydrolysis of phosphatidylcholine, whereas $p h o A$, and $p h o B$ encode alkaline phosphatases (APases) which facilitate the recovery of inorganic phosphate from organic sources (Hulett et al., 1990). As B.subtilis NCD-2 has the ability of solubilizing phosphatidylcholine and the phoR disrupted mutant lost phosphatidylcholine-solubilizing ability, solubilizing phosphatidylcholine in NCD-2 may due to PDase. The phoR disrupted mutant grew slower on Mongina organic phosphate culture medium than NCD-2 wild type, a result of less phosphate obtained by mutant. This result indicated that the PhoP/PhoR two-component system may be involved in phosphatidylcholine-solubilization.

Rhizosphere competence and colonization are important prerequisites in effective biological control by biocontrol agents (Compant et al., 2005). Bio-control agent competence greatly depends on the ability to either take advantage of a specific environment or on their abilities to adapt to changing conditions (Ravel and Cornelis, 2003). Soluble phosphorus in the soil is usually very scarce, although other organic phosphate compounds in the form of phosphodiesters may also exist in soil (Rodriguez and Fraga, 1999). Thus we hypothesize that NCD-2 is capable of growing rapidly and becoming predominant by hydrolyzing phosphodiesters and acquired inorganic phosphate from the soil. From a previous study, it was deduced that $B$. subtilis NCD-2 has the capacity of efficiently colonizing the surface of cotton roots (Ma, unpublished). In this study, the cell density of $B$. subtilis NCD-2 and derivative strains in the rhizosphere of cotton were compared, whereby it was found that the population of $p h o R$ disrupted mutants therein decreased sixteen days after sowing, although this tendency could be reversed by complementation with phoR. Therefore, rhizosphere competence and colonization may be other factors controlled by the PhoR/PhoP system, besides contributing to the effective suppression of cotton verticillum wilt and cotton seedlings damping-off by NCD-2 in the field.

\section{Acknowledgments}

This work was funded by the Chinese National Natural Science Foundation (30671401), Chinese National Programs for High Technology Research and Development (2006AA10A211), and the Chinese MOST-DEST Cooperation Project (2007DFA31570).

\section{References}

Allenby NEE, Connor NO, Pragain Z, Ward AC, Wipat A and Harwood CR (2005) Genome-wide transcriptional analysis of the phosphate starvation stimulon of Bacillus subtilis. J Bacteriol 187:8063-8080.

Antelmann H, Scharf C and Hecker M (2000) Phosphate starvation inducible proteins of Bacillus subtilis: Proteomics and transcriptional analysis. J Bacteriol 182:4478-4490.

Bookstein C, Edwards CW, Kapp NV and Hulett FM (1990) The Bacillus subtilis 168 alkaline phosphatase III gene: Impact of a phoAIII mutation on total alkaline phosphatase synthesis. J Bacteriol 172:3730-3737.

Cintas LM, Rodriguez JM, Fernandez MF, Sletten K, Nes IF, Hernandez PE and Holo H (1995) Isolation and characterization of pediocin L50, a new bacteriocin from Pediococcus acidilactici with a broad inhibitory spectrum. Appl Environ Microbiol 61:2643-2648.

Compant S, Duffy B, Nowak J, Clement C and Barka EA (2005) Use of plant growth-promoting bacteria for biocontrol of plant diseases: Principles, mechanisms of action, and future prospects. Appl Environ Microbiol 71:4951-4959.

Darmon E, Noone D, Masson A, Bron S, Kuipers OP, Devine KM and van Dijl JM (2002) A novel class of heat and secretion stress-responsive genes is controlled by the autoregulated CssRS two-component system of Bacillus subtilis. J Bacteriol 184:5661-5671. 
Eder S, Liu W and Hulett FM (1999) Mutational analysis of the phoD promoter in Bacillus subtilis: Implications for PhoP binding and promoter activation of Pho regulon promoters. J Bacteriol 181:2017-2025.

Fradin EF and Thomma BPHJ (2006) Physiology and molecular aspects of verticillium wilt diseases caused by $V$. dahliae and V. albo-atrum. Mol Plant Pathol 7:71-86.

Fukuchi K, Kasahara Y, Asai K, Kobayashi K, Moriya S and Ogasawara N (2000) The essential two-component regulatory system encoded by $y y c F$ and $y y c G$ modulates expression of the ftsAZ operon in Bacillus subtilis. Microbiology 146:1573-1583.

Handelsman J and Stabb EV (1996) Biocontrol of soilborne plant pathogens. Plant Cell 8:1855-1869.

Hoch JA (2000) Two-component and phosphorelay signal transduction. Curr Opin Microbiol 3:165-170.

Hulett FM, Bookstein C and Jensen K (1990) Evidence for two structural genes for alkaline phosphatase in Bacillus subtilis. J Bacteriol 172:735-740.

Le Hegarat JC and Anagnostopoulos C (1973) Purification, subunit structure and properties of two repressible phosphohydrolases of Bacillus subtilis. Eur J Biochem 39:525-539.

Leclere V, Bechet M, Adam A, Sebastien JG, Wathelet B, Ongena M, Thonart P, Gancel F, Chollet IM and Jacques P (2005) Mycosubtilin overproduction by Bacillus subtilis BBG100 enhances the organism's antagonistic and biocontrol activities. Appl Environ Microbiol 71:4577-4584.

Leifert C, Li H, Chidburee S, Hampson S, Workman S, Sigee D, Epton HAS and Harbour A (1995) Antibiotic production and biocontrol activity by Bacillus subtilis CL27 and Bacillus pumillus CL45. J Appl Bacteriol 78:97-108.

Li SZ, Lu XU, Ma P, Gao SG, Liu XZ and Liu G (2005) Evaluation of biocontrol potential of a bacterial strain NCD-2 against cotton verticillium wilt in field trials. Acta Phytopathol Sinica 35:451-455.

Martin JF (2004) Phosphate control of the biosynthesis of antibiotics and other secondary metabolites is mediated by the PhoR-PhoP system: An unfinished story. J Bacteriol 186:5197-5201.

Martin PA, Lohr JR and Dean DH (1981) Transformation of Bacillus thuringiensis protoplasts by plasmid deoxyribonucleic acid. J Bacteriol 146:980-983.

Olsen SR and Sommers LE (1982) Phosphorus, in Methods of Soil Analysis, Part 2: Chemical and Microbiological Properties. 2nd edition. American Society of Agronomy and Soil Science Society of America Press, Madison, pp 403-430.

Ongena M, Duby F, Rossignol F, Fauconnier ML, Dommes J and Thonart P (2004) Stimulation of the lipoxygenase pathway is associated with systemic resistance induced in bean by a non-pathogenic Pseudomonas strain. Mol Plant-Microbe Interact 17:1009-1018.

Parkinson JS and Kofoid EC (1992) Communication modules in bacterial signaling proteins. Annu Rev Genet 26:71-112.

Podile AR and Prakash AP (1996) Lysis and biological control of Aspergillus niger by Bacillus subtilis AF1. Can J Microbiol 42:533-538.

Raso J, Palop A, Pagan R and Condon S (2008) Inactivation of Bacillus subtilis spores by combining ultrasonic waves under pressure and mild heat treatment. J Appl Microbiol 85:849-854.

Ravel J and Cornelis P (2003) Genomics of pyoverdine-mediated iron uptake in Pseudomonads. Trends Microbiol 11:195200.

Rodriguez H and Fraga R (1999) Phosphate solubilizing bacteria and their role in plant growth promotion. Biotechnol Adv 17:319-339.

Sola-Landa A, Moura RS and Martin JF (2003) The two-component PhoR-PhoP system controls both primary metabolism and secondary metabolite biosynthesis in Streptomyces lividans. PNAS 100:6133-6138.

Tjamos EC, Rowe RC, Heale JB and Fravel DR (2000) Advances in Verticillium Research and Disease Management. APS Press, American Phytopathological Society, 109 pp.

Tjamos EC, Tsitsigiannis DI, Tjamos SE, Antoniou P and Katinakis $P$ (2004) Selection and screening of endorhizosphere bacteria from solarised soils as biocontrol agents against Verticillium dahliae of solanaceous hosts. Eur J Plant Pathol 110:35-44.

Toure Y, Ongena M, Jacques P, Guiro A and Thonart P (2004) Role of lipopeptides produced by Bacillus subtilis GA1 in the reduction of grey mould disease caused by Botrytis cinerea on apple. J Appl Microbiol 96:1151-1160.

Tsuge K, Ano T, Hirai M, Nakamura Y and Shoda M (1999) The genes $\operatorname{deg} Q$, pps, and lpa-8 (sfp) are responsible for conversion of Bacillus subtilis 168 to plipastatin production. Antimicrob Agents Chemother 43:2183-2192.

Weller DM, Raaijmakers JM, Gardener BB and Thomashow LS (2002) Microbial populations responsible for specific soil suppressiveness to plant pathogens. Annu Rev Phytopathol 40:309-348.

Associate Editor: Luis Carlos de Souza Ferreira

License information: This is an open-access article distributed under the terms of the Creative Commons Attribution License, which permits unrestricted use, distribution, and reproduction in any medium, provided the original work is properly cited. 